\title{
Etilendiamin tetraasetik asit ve etidronik asitin Biodentine yüzey pürüzlülüğü üzerine etkisi: in vitro
}

\author{
Özgür Illke Atasoy Ulusoy, ${ }^{1 *}$ Yelda Nayir Paltun, ${ }^{1}$ \\ Nuran Ulusoy ${ }^{2}$ \\ ${ }^{1}$ Endodonti Anabilim Dalı, Diş Hekimliği Fakültesi, Gazi \\ Üniversitesi, Ankara, Türkiye, ${ }^{2}$ Restoratif Tedavi Anabilim Dalı, \\ Diş Hekimliği Fakültesi, Yakın Doğu Üniversitesi, Lefkoşa, \\ Kuzey Kıbrıs Türk Cumhuriyeti
}

\section{ÖZET}

AmAÇ: Bu çalışmanın amacı $\% 9$ etidronik asit (HEBP) ve $\% 17$ etilendiamin tetraasetik asitin (EDTA) Biodentine yüzey pürüzlülüğü üzerine etkilerini değerlendirmektir.

GereÇ VE YönTEM: Biodentine (Septodont) üretici firma talimatları doğrultusunda karıştırıldı. Kısaca, tek doz toz içeren kapsül içerisine 5 damla likit eklendi. Daha sonra kapsül, karıştırıcıda $\mathbf{3 0}$ sn karıştırıldı. Hazırlanan karışım 5 $\mathrm{mm}$ çapında, $3 \mathrm{~mm}$ derinliğinde çelik kalıp içine yerleştirildi. Biodentine yüzeyleri silikon karbid zımpara kağıtlarla parlatıldı. Otuz örneğin başlangıç yüzey pürüzlülüğü, portatif yüzey pürüzlük cihazı (Perthometer M2) kullanılarak ölçüldü. Bu amaçla, örneklerin üç farklı bölgesine $0.8 \mathrm{~mm} /$ sn hızla $5 \mathrm{mN}$ kuvvet uygulandı. Örnekler kullanılan irrigasyon solüsyonuna göre iki gruba ayrıldı $(n=15)$. Birinci gruptaki örneklere \%9 HEBP, ikinci gruptaki örneklere \%17 EDTA uygulandı. Örneklerin yüzey pürüzlülüğü irrigasyon uygulamasından sonra 1. ve 2. dakikalarda ölçüldü. Bütün zaman dilimlerinde, her bir örneğin üzerinde farklı bölgelerden 3 ölçüm yapıldı. Veri tek yönlü ANOVA ve bağımsız örneklem t-testi ile istatistiksel olarak analiz edildi.

BULGULAR: HEBP grubunda 0., 1. ve 2. dakika değerleri arasında fark yoktu ( $p=0.107$; ANOVA). Biodentine yüzey pürüzlülüğü değerleri, EDTA kullanımında, 1. dakika sonunda bașlangıç değerlerine göre istatistiksel olarak anlamlı şekilde arttı ( $p<0.001$; t-testi). İki zaman dilimindeki yüzey pürüzlülük değişimleri EDTA ve HEBP grupları arasında istatistiksel olarak farklıydı ( $0-1$ dakika geçişi için $p=0.003$, 1-2 dakika geçişi için $p=0.021$ ).

Sonuç: Perforasyon tedavisi ve kök kanal tedavisi sırasında \%17 EDTA kullanımı Biodentine yüzeyinde bozulmalara neden olabilmektedir.

ANAHTAR Kelimeler: Endodonti; kalsiyum silikat; yüzey özellikleri

Makale gönderiliş tarihi: 22 Haziran 2016; Yayına kabul tarihi: 30 Ekim 2016 *iletișim: Dr. Özgür İlke Atasoy Ulusoy, Gazi Üniversitesi, Diş Hekimliği

Fakültesi, Endodonti AD, 8. Cadde, 06510, Emek, Ankara, Türkiye

E-posta: ilkeatasoy@yahoo.com
KaYNAK GöSTERmeK İçin: Atasoy Ulusoy Öi, Nayir Paltun Y, Ulusoy N. Etilendiamin tetraasetik asit ve etidronik asitin Biodentine yüzey pürüzlülüğü üzerine etkisi: in vitro. Acta Odontol Turc 2017;34(1):19-23

EDiтöR: Güven Kayaoğlu, Gazi Üniversitesi, Ankara, Türkiye

YAYIN HAKKI: (C) 2017 Atasoy Ulusoy ve ark. Bu eserin yayın hakkı Creative Commons Attribution License ile ruhsatlandırılmıştır. Sınırsız kullanım, dağıtım ve her türlü ortamda çoğaltım, yazarlar ve kaynağın belirtilmesi kaydıyla serbesttir.

[Abstract in English is at the end of the manuscript]

\section{Giriş}

Kalsiyum silikat esaslı kök kanal patları, gösterdikleri biyouyumluluk ve yüksek sızdırmazlık özellikleri nedeniyle son yıllarda popüler hale gelmiştir. ${ }^{1}$ Bu nedenle bu materyallerin, vital pulpa tedavileri, apeksifikasyon, kök rezorpsiyonu ve perforasyon tedavisi gibi sert doku tamiri beklenen durumlarda kullanımı tercih edilmektedir. ${ }^{2}$ Trikalsiyum oksit ve diğer mineral oksitleri içeren mineral trioksit agregat (MTA), uzun yıllardır kliniklerde retrograd kanal dolgusu, apeksifikasyon ve pulpa kuafajında başarılı olarak kullanılmaktadır. ${ }^{3}$ Ancak MTA'nın manipülasyon zorluğu, dişlerde renklenme oluşturma gibi dezavantajları, yeni arayışlara neden olmuştur. Biodentine (Septodont, Saint Maur des Fosses, Fransa), trikalsiyum silikat, kalsiyum karbonat, zirkonyum oksit ve su bazlı likid içeren, yakın tarihte piyasaya sunulmuş kalsiyum silikat esaslı bir simandır ve mineral trioksit agregat ile aynı klinik durumlarda kullanılmaktadır. Ayrıca diğer kalsiyum silikat esaslı materyallere göre Biodentine'nin dentine daha iyi bağlanma yeteneğinin bulunduğu ileri sürülmektedir. ${ }^{4,5}$

Kök kanal tedavisinde, kök kanal dolgusundan önce smear tabakasının kaldırılması gerekliliği bir çok araştırmacı tarafından kabul görmektedir. ${ }^{6,7}$ Bu amaçla en çok kullanılan şelasyon ajanlarından biri etilendiamin tetraasetik asittir (EDTA). Ancak EDTA'nın kök kanaIının apikal üçlüsünde bulunan smear tabakasını uzaklaştırmaktaki yetersizliği, $\mathrm{NaOCl}$ ile etkileşime girmesi ve 1 dakikadan fazla uygulandığında kök kanal dentininde erozyon oluşturması, farklı asitlerin gündeme gelmesine neden olmuştur. ${ }^{8,9}$ Etidronik asit diye de bilinen 1-hydroxyethylidene-1, 1-bisphosphonate (HEBP), Na$\mathrm{OCl}$ ile kullanıldığında smear tabakasını etkin şekilde 
uzaklaştırmıştır. ${ }^{10}$ Ayrıca kök kanal dentininde EDTA'ya göre daha az agresif olduğu bildirilmiştir. ${ }^{11}$

Kök kanallarında, kalsiyum silikat esaslı materyallerle yapılan perforasyon tamiri, apeksifikasyon gibi tedavilerden sonra kullanılan irrigasyon ajanları, bu materyallerin yapısında bozulmalara neden olabilir. Özellikle kullanılan şelasyon ajanları, kalsiyum bağlama potansiyellerinden dolayı, kalsiyum silikat bazlı patların istenen yüzey özelliklerini bozarak yüzey pürüzlülüğüne ve yüzey sertliğinde azalmaya neden olabilir. Bu nedenle bu çalışmanın amacı, \%9 etidronik asit ve \%17 EDTA'nın iki farklı zaman diliminde Biodentine'nin yüzey pürüzlülüğü üzerindeki etkilerini incelemektir.

\section{Gereç ve Yöntem}

Biodentine (Septodont, Saint Maur des Fosses, Fransa), üretici firmanın talimatlarına göre hazırlandı. Trikalsiyum silikat, kalsiyum karbonat, zirkonyum oksitten oluşan tozu içeren kapsül açılarak, sodyum, magnezyum, klor, kalsiyum ve sudan oluşan likidin beş damlası toza eklendi. Kapsül karıştırıcıya yerleştirilerek 30 sn boyunca karıştırıldı. Hazırlanmış Biodentine, kitin içinde bulunan spatül yardımıyla kapsülden alındı. $5 \mathrm{~mm}$ çap ve $3 \mathrm{~mm}$ derinliğe sahip otuz adet çelik kalıba bir amalgam tabancası kullanılarak yerleştirildi. Açıkta kalan Biodentine yüzeyleri pürüzlülük testi için, dönen aşındırma makinesine (Mecapol P230, Brieet Angonues, Fransa) monte edilmiş, sırasıyla 800, 1000, 1200 grite sahip silikon karbid zımpara kağıtlarla distile su altında düzeltildi ve cilalandı. Tüm 30 örneğin başlangıç yüzey pürüzlülüğü (Ra, $\mu \mathrm{m})$, portatif yüzey pürüzlülük test cihazı (Perthometer M2, Mahr GmbH, Gottingen, Almanya) kullanılarak ölçüldü. Test cihazının ölçme kuvveti $5 \mathrm{mN}$ ve ilerleme hızı 0.8 $\mathrm{mm} / \mathrm{sn}$ olarak belirlendi. Her örneğin birbirine yakın olacak şekilde farklı üç bölgesinden ölçüm yapıldı ve bu bölgeler işaretlendi. Üç ölçümün aritmetik ortalaması alınarak, bu değer o örneğin o zamandaki ortalama Ra değeri olarak kaydedildi. Ardından örnekler, kullanılan irrigasyon solüsyonlarına göre iki gruba ayrıldı $(n=15)$. Birinci gruptaki örneklere, \%17 EDTA (Werax, İzmir, Türkiye), ikinci gruptaki örneklere ise $\% 9$ etidronik asit (Sigma Aldrich, St Louis, MO, ABD) uyguland.

EDTA (\%17), piyasada bu konsantrasyondaki hazır solüsyonlardan elde edilirken, \%9 etidronik asit, \%60 konsantrasyonun saf suyla karıştırılarak seyreltilmesi yoluyla elde edildi ve kullanıma kadar cam şişe içinde oda sıcaklığında saklandı. İrrigasyon solüsyonları, 30-G enjektör iğneleri kullanılarak, herhangi bir aktivasyon yapılmadan uygulandı. Örneklerin yüzey pürüzlülükleri, irrigasyon uygulamasının ardından birinci ve ikinci dakikanın sonunda işaretli noktalardan tekrar ölçüldü.

Elde edilen veriler, SPSS 20 istatistik yazılımı (SPSS Inc., Chicago, IL, ABD) kullanılarak değerlendirildi. Verilerin istatistiksel olarak analizinde tek yönlü tekrarlı ölçümler ANOVA ve bağımsız örnek t-testi kullanıldı. İstatistiksel olarak anlamlılık düzeyi $p<0.05$ kabul edildi.

\section{BULGULAR}

Örneklerin irrigasyon solüsyonu kullanımı sonrası ortalama yüzey pürüzlülük ve standart sapmalarının başlangıç (0), 1.ve 2. dakikadaki değerleri Tablo 1'de gösterilmektedir.

Biodentine yüzey pürüzlülüğü \%17 EDTA kullanılan grupta, 1. dakikanın sonunda istatistiksel olarak anlamIı bir şekilde artış gösterdi $(p<0.001)$. Ancak, birinci ve ikinci dakikanın sonundaki yüzey pürüzlülüğü değerleri arasındaki fark istatistiksel olarak anlamlı değildi $(p>0.05)$.

Diğer grupta (\%9 HEBP) ise 0., 1. ve 2. dakikanın sonunda Biodentine yüzey pürüzlülüğü değerleri arasında istatistiksel olarak anlamlı bir fark yoktu $(p=0.107$; ANOVA). Yani etidronik asit kullanımı, iki zaman diliminde Biodentine'nin yüzey pürüzlüğünde herhangi bir artışa neden olmadı.

İki farklı asit kullanımı sonrasında, Biodentine yüzey pürüzlülüğündeki zamana bağlı değişim Tablo 2'de gösterilmektedir. Başlangıç ve 1. dakika arasındaki yüzey pürüzlülük değişimleri EDTA ve HEBP kullanılan gruplar arasında istatistiksel olarak farklıydı $(p=0.003)$. Yine, 1. ve 2. dakikalar arasındaki yüzey pürüzlülük değişimleri iki grup arasında istatistiksel olarak farklıydı $(p=0.021)$.

\section{TARTIŞMA}

Kalsiyum silikat simanlar, kök rezorpsiyonlarının tedavisinde, kök kanal tedavisi sırasında istenmeden

Tablo 1. İrigasyon solüsyonlarının kullanımı sonrası Biodentine ortalama yüzey pürüzlülük değerleri ve standart sapmaları $(R a)$, ve bu değerler arasındaki istatistiksel karşılaştırma

\begin{tabular}{cccc}
\hline Zaman & $\begin{array}{c}\text { Örnek } \\
\text { sayısı (n) }\end{array}$ & \multicolumn{2}{c}{ Irrigasyon solüsyonu } \\
\%9 HEBP & $\% 17$ EDTA \\
\hline 0. dk & 15 & $1.091 \pm 0.632^{\mathrm{a}}$ & $0.736 \pm 0.197^{\mathrm{a}}$ \\
1. dk & 15 & $0.919 \pm 0.331^{\mathrm{a}}$ & $1.055 \pm 0.281^{\mathrm{b}}$ \\
2. dk & 15 & $0.803 \pm 0.413^{\mathrm{a}}$ & $1.142 \pm 0.364^{\mathrm{b}}$ \\
p değeri (ANOVA) & 0.107 & $<0.001$ \\
\hline
\end{tabular}

Sütunlar için farklı üstsimge harfler ölçümler arasında istatistiksel olarak anlamlı farka işaret etmektedir.

Tablo 2. İrigasyon solüsyonlarının kullanımından sonra Biodentine yüzey pürüzlülüğündeki zamana bağlı değişimlerin ortalama (Ort) ve standart sapma değerleri (Ra), ve bu değerler arasındaki istatistiksel karşılaştırmalar

\begin{tabular}{|c|c|c|c|c|}
\hline & $\begin{array}{c}\text { Örnek } \\
\text { sayısı (n) }\end{array}$ & \%9 HEBP & \%17 EDTA & $\begin{array}{c}\text { p-değeri } \\
\text { (t-test) }\end{array}$ \\
\hline $\begin{array}{l}0 . \text { ve } 1 . \\
\text { dakikalar } \\
\text { arasındaki } \\
\text { yüzey } \\
\text { pürüzlülük } \\
\text { farkı }\end{array}$ & 15 & $-0.173 \pm 0.533$ & $0.319 \pm 0.261$ & 0.003 \\
\hline $\begin{array}{l}\text { 1. ve } 2 \text {. } \\
\text { dakikalar } \\
\text { arasındaki } \\
\text { yüzey } \\
\text { pürüzlülük } \\
\text { farkı }\end{array}$ & 15 & $-0.115 \pm 0.273$ & $0.087 \pm 0.166$ & 0.021 \\
\hline
\end{tabular}


oluşan perforasyonların tamirinde, apeksi kapanmamış veya periapikal cerrahi geçirmiş köklerin doldurulmasında ve vital pulpa tedavilerinde yaygın olarak kullanılmaktadır. ${ }^{2,3}$ Günümüzde en çok tercih edilen kalsiyum silikat siman, yüksek sızdırmazlık ve biyouyumluluk gibi özelliklere sahip mineral trioksit agregattır (MTA). ${ }^{12}$ Ancak MTA'nın yapısından dolayı manipülasyon zorluğu sergilemesi, uzun sertleşme süresine sahip olması, dişlerde renkleşme oluşturması gibi dezavantajları nedeniyle, yüksek mekanik özellikler ile biyouyumluluğu yapısında birleştirmiş ve 12 dakikalık sertleşme süresine sahip bir malzeme olan Biodentine gündeme gelmiştir. ${ }^{13-15}$ Ayrıca pürüzlülük ve sertlik çalışmalarında MTA ile çalışma güçlüğü bulunması nedeniyle bu çalışmada Biodentine kullanılmıştır.

Etilendiamin tetraasetik asit, kök kanal tedavisinde smear tabakanın kaldırılması amacıyla yaygın olarak kullanılan bir şelasyon ajanıdır. Ancak $\mathrm{NaOCl}$ ile birlikte kullanıldığında, $\mathrm{NaOCl}$ ile etkileşime geçerek, materyalin serbest klor oranını düşürdüğü, antimikrobiyal ve doku çözücü etkisini azalttığı ileri sürülmektedir..$^{9,10}$ Daha zayıf bir şelatör olan etidronik asit ise $\mathrm{NaOCl}$ ile kullanıldığında hem böyle bir etkileşime girmez, hem de EDTA ile karşılaştırılabilir düzeyde smear tabakayı kaldırabilme özelliğine sahiptir. ${ }^{10,16} \mathrm{Bu}$ nedenle, bu çaIışmada kullanılan perforasyon tamir materyaline olan etkisinin de daha az olacağı düşünülmüş ve $\% 9$ etidronik asit kullanımı sonucu Biodentine yüzeyinde oluşan yüzey pürüzlülüğü \%17 EDTA ile karşılaştırılmıştır. Yapılan çalışmalarda, smear tabakanın kaldırılması amacıyla, etidronik asitin \%18 ve \%9 konsantrasyonları kullanıımıştır. Bu nedenle bu çalışmada kullanılan kalsiyum silikat simanın yapısını daha az etkileyeceği düşüncesiyle \%9'luk konsantrasyonun kullanılması tercih edilmiştir. Ancak \%18 konsantrasyonda etidronik asit ve diğer şelasyon ajanlarının kalsiyum silikat siman üzerindeki etkilerini de karşılaştıran ileri çalışmalar da yapılmalıdır.

Bu çalışmada, etilendiamin tetraasetik asit kullanımı, etidronik asit kullanımına göre Biodentine'nin yüzey pürüzlülüğünde daha fazla artışa neden olmuştur. Bunun nedeni, etidronik asitin EDTA'ya göre daha zayıf şelasyon yapması, dolayısıyla simanın yapısındaki kalsiyum iyonları üzerinde daha az etkili olması olabilir. ${ }^{17}$ Ancak her iki grupta da 1. ve 2. dakikalar sonunda Biodentine yapısında meydana gelen pürüzlülük değerlerinin istatistiksel olarak değişmemesi, kullanılan solüsyonların kendi kendini sınırlayıcı etkisini gündeme getirmektedir. EDTA'nın disodyum tuzları kalsiyumla birleştiği zaman bir denge oluşur ve daha fazla birleşme gerçekleşmez. ${ }^{18}$ Dolayısıyla EDTA'nın şelasyon kapasitesinin bir limiti bulunmaktadır. Bu çalışmada, 1. ve 2. dakikanın sonundaki siman yüzey yapısı ölçümlerinde fark gözlenmemesi, bu limitli etkiyi bir kez daha doğrulamaktadır. Etidronik asit grubunda da zamana bağlı farkın gözlenmemiş olması, bu ajanın da şelasyon kapasitesinin kendi kendini sınırlayabildiğini düşündürmektedir. Yapılan çalışmalarda, 1 dakikadan uzun süre uygulanan EDTA'nın kök kanal dentininde erozyon oluşturduğu bidirilmiş ve uygulamanın 1 dakika ile sınırlandırılması önerilmiştir. ${ }^{8}$ Ancak, EDTA'nın kök kanalında daha uzun süreler uygulandığı diğer çalışmalarda böyle bir etki gösterilmemiştir. ${ }^{19,20}$ Bu bilgilerin ışığı altında biz de çalışmamızda şelasyon ajanlarının etkilerini değerlendirmek amacıyla 1 ve 2 dakikalık uygulamaları tercih ettik.

Üç zaman dilimi arasındaki pürüzlülük değerlerindeki değişim incelendiğinde, yine \%17 EDTA grubunda 0. ve 1. dakikalar ile 1. ve 2. dakikalar arasında meydana gelen pürüzlülük farkları, $\% 9$ etidronik asit grubundan istatistiksel olarak yüksektir. Etilendiamin tetraasetik asit kullanıldıktan 1 ve 2 dakika sonra elde edilen pürüzlülük değerleri her ne kadar istatistiksel olarak benzer olsa da, zaman dilimleri arasında elde edilen fark, etkinin az da olsa devam ettiğine işaret etmektedir. Oysaki etidronik asit kullanıldığında, zaman dilimleri arasında negatif yönde bir artış meydana gelmektedir. Kullanılan asit solüsyonlarının dolgu materyallerinin yüzeyini daha pürüzsüz hale getireceğini düşünmediğimiz için, etidronik asit uygulama sonrasında elde edilen daha düşük pürüzlülük değerleri, ölçüm sırasında kullanılan cihaza bağlı oluşabilecek sapmalarla ilişkilendirilebilir. Bu olası hataları minimuma indirgemek için üç ayrı noktadan yapılan ölçümlerin aritmetik ortalaması alınmış olsa da, örnek yüzeyinden veya deney düzeneğinden doğan varyasyonların sonuçları değiştirmeyecek düzeyde bir etkisi olabilir.

Diş hekimliğinde kullanılan materyallerin yüzeylerinde meydana gelen bozulmaların saptanması, kullanılan solüsyonların diş yüzeylerinde oluşturduğu yüzey değişikliklerinin ölçülmesi gibi amaçlarla profilometre, portatif veya bilgisayarlı pürüzlülük ölçüm cihazı ve atomik kuvvet mikroskobu gibi yöntemler kullanılmaktadır. ${ }^{21}$ Bunların arasında atomik kuvvet mikroskopu (AFM), biyolojik örneklerin morfolojileri ve mekanik özellikleri hakında detaylı üç boyutlu bilgi veren bir araçtır. AFM'nin görüntüleme yöntemi non-invaziv olup, havada veya farklı fizyolojik durumlarda hasar yaratmadan görüntü alınmasına olanak tanımaktadır. ${ }^{22}$ Portatif yüzey pürüzlülük ölçüm cihazı olan profilometre ise oldukça pratik bir yöntem olup, gerçeğe çok yakın nesnel veriler sunmaktadır. Bu çalışmada yapılan yüzey ölçümleri portatif yüzey pürüzlülük ölçüm cihazı kullanılarak elde edilmiştir. Ancak AFM gibi üç boyutlu ve daha detaylı bilgi sunan yöntemler kullanılarak yapılacak daha ileri çalışmalar da gerekmektedir.

Kök kanal tedavisinde smear tabakasının kaldırılması amacıyla kullanılan irrigasyon solüsyonlarının kök kanal dentini üzerindeki etkileri kadar, kök kanalında daimi olarak kullanılan dolgu materyalleri üzerindeki etkileri de önemlidir. Her ne kadar bu solüsyonların kullanımından sonra bu etkileşimi önleyebilmek ve kanalda artık kalmaması amacıyla distile su ile yıkama yapılsa da, kalan miktarlar kullanılan materyallerin yüzeyini etkileyebilir. Hatta, perforasyon tamiri ve apikal tıkama amacıyla yerleştirilen kalsiyum silikat simanlardan sonra uygulanan şelasyon ajanları, bu simanların yapı- 
sında çok ciddi bozulmalara neden olabilir. Bu bozulma da, klinik olarak tamir materyalinin dentine bağlanmasını ve üzerine gelen baskı kuvvetlerine dayanımını azaltabilir, ayrıca mikroorganizmalar için ek bir tutucu yüzey oluşturabilir. Tüm bu nedenlerden dolayı, kök kanal tedavisinde kalsiyum silikat simanların kullanılacağı durumlarda, bu simanların yüzey yapılarını etkilemeyecek irrigasyon solüsyonları tercih edilmelidir.

\section{Sonuç}

Kök kanal tedavisinde son irrigasyon solüsyonu olarak kullanılan etilendiamin tetraasetik asit, kalsiyum silikat simanların yapısında bozulmaya neden olabilir. Bu nedenle kalsiyum silikat simanların kullanılacağı durumlarda, smear tabakanın kaldırılması amacıyla yüzey pürüzlülüğüne neden olmayacak daha zayıf asitlerin kullanımı tercih edilebilir.

Çıkar çatışması: Yazarlar bu çalışmayla ilgili herhangi bir çıkar çatışmalarının bulunmadığını bildirmişlerdir.

\section{KAYNAKLAR}

1. Sarkar NK, Caicedo R, Ritwik P, Moiseyeva R, Kawashima I. Physicochemical basis of the biologic properties of mineral trioxide aggregate. J Endod 2005;31:97-100.

2. Parirokh M, Torabinejad M. Mineral trioxide aggregate: a comprehensive literature review-part III: clinical applications, drawbacks, and mechanism of action. J Endod 2010;36:400-13.

3. Torabinejad M, Chivian N. Clinical applications of mineral trioxide aggregate. J Endod 1999;25:197-205.

4. Guneser MB, Akbulut MB, Eldeniz AU. Effect of various endodontic irrigants on the push-out bond strength of biodentine and conventional root perforation repair materials. J Endod 2013;39:380-4.

5. El-Ma'aita AM, Qualtrough AJE, Watts DC. The effect of smear layer on the push-out bond strength of root canal calcium silicate cements. Dent Mater 2013;29:797-803.

6. Torabinejad M, Handysides R, Khademi AA, Bakland LK. Clinical implications of the smear layer in endodontics: a review. Oral Surg Oral Med Oral Pathol Oral Radiol Endod 2002;94:658-66.

7. Economides N, Liolios E, Kolokuris I, Beltes P. Long-term evaluation of the influence of smear layer removal on the sealing ability of different sealers. J Endod 1999;25:123-5.

8. Calt S, Serper A. Time-dependent effects of EDTA on dentin structures. J Endod 2002;28:17-9.

9. Grawehr M, Sener B, Waltimo T, Zehnder M. Interactions of ethylenediamine tetraacetic acid with sodium hypochlorite in aqueous solutions. Int Endod J 2003;36:411-7.

10. Zehnder M, Schmidlin P, Sener B, Waltimo T. Chelation in root canal therapy reconsidered. J Endod 2005;31:817-20.

11. Lottanti S, Gautschi H, Sener B, Zehnder M. Effects of ethylenediaminetetraacetic, etidronic and peracetic acid irrigation on human root dentine and the smear layer. Int Endod J 2009;42:335-43.

12. Torabinejad $M$, Parirokh M. Mineral trioxide aggregate: a comprehensive literature review--part II: leakage and biocompatibility investigations. J Endod 2010;36:190-202.

13. Torabinejad M, Hong CU, McDonald F, Pitt Ford TR. Physical and chemical properties of a new root-end filling material. $J$ Endod 1995;21:349-53.

14. Boutsioukis C, Noula G, Lambrianidis T. Ex vivo study of the efficiency of two techniques for the removal of mineral trioxide aggregate used as a root canal filling material. J Endod 2008;34:1239-42.
15. Caronna V, Himel V, Yu Q, Zhang J-F, Sabey K. Comparison of the surface hardness among 3 materials used in an experimental apexification model under moist and dry environments. J Endod 2014;40:986-9.

16. De-Deus G, Zehnder M, Reis C, Fidel S, Fidel RA, Galan J Jr, et al. Longitudinal co-site optical microscopy study on the chelating ability of etidronate and EDTA using a comparative single-tooth model. J Endod 2008;34:71-5.

17. Tartari T, Duarte Junior AP, Silva Júnior JO, Klautau EB, Silva E Souza Junior MH, Silva E Souza Junior Pde A. Etidronate from medicine to endodontics: effects of different irrigation regimes on root dentin roughness. J Appl Oral Sci 2013;21:409-15.

18. Hülsmann $M$, Heckendorff $M$, Lennon $A$. Chelating agents in root canal treatment: mode of action and indications for their use. Int Endod J 2003;36:810-30.

19. Ulusoy Öi, Görgül G. Effects of different irrigation solutions on root dentine microhardness, smear layer removal and erosion. Aust Endod J 2013;39:66-72.

20. Kumar Y, Lohar J, Bhat S, Bhati M, Gandhi A, Mehta A. Comparative evaluation of demineralization of radicular dentin with $17 \%$ ethylenediaminetetraacetic acid, $10 \%$ citric acid, and MTAD at different time intervals: An in vitro study. J Int Soc Prev Community Dent 2016;6:44-8.

21. Hu X, Ling J, Gao Y. Effects of irrigation solutions on dentin wettability and roughness. J Endod 2010;36:1064-7.

22. Ma S, Cai J, Zhan X, Wu Y. Effects of etchant on the nanostructure of dentin: an atomic force microscope study. Scanning 2009;31:28-34.

\section{Effect of ethylenediamine tetraacetic acid and etidronic acid on the surface roughness of Biodentine: in vitro}

\begin{abstract}
OBJECTIVE: The aim of this study was to evaluate the effect of $9 \%$ etidronic acid (HEBP) and $17 \%$ ethylenediamine tetraacetic acid (EDTA) on the surface roughness of Biodentine.
\end{abstract}

Materials And Method: Biodentine (Septodont) was mixed according to the manufacturer's instructions. Briefly, five drops of liquid were added into the capsule containing the powder. Then the capsule was placed in a triturator for $30 \mathrm{sec}$. The prepared mixture was placed into a mold (diameter: $5 \mathrm{~mm}$, depth: $3 \mathrm{~mm}$ ). The Biodentine surfaces were polished with silicon carbide abrasive papers. The surface roughness of $\mathbf{3 0}$ samples was measured at baseline using a portable surface roughness tester. For this purpose, a $5 \mathrm{mN}$ force was applied onto three different locations of the samples with a speed of $0.8 \mathrm{~mm} / \mathrm{sec}$. The samples were divided into two groups according to the irrigation solution $(n=15)$; first group was treated with $9 \%$ HEBP, and the second group was treated with 17\% EDTA. The surface roughness of the samples was measured again after 1 and 2 min of irrigant application. Data were statistically analyzed using one-way ANOVA and independent sample t-test.

RESULTS: For HEBP, no significant difference was found between the surface roughness values at $0 ., 1$., and $2 \mathrm{~min}$ $(p=0.107$; ANOVA). For EDTA, the surface roughness value at $1 \mathrm{~min}$ was significantly greater than the baseline value ( $p<0.001$; t-test). The surface roughness changes at 
the two time periods were significantly different between the EDTA and HEBP groups $(p=0.003$ for $0-1 \mathrm{~min}$ passage, $p=0.021$ for $1-2 \min$ passage).

Conclusion: The use of $17 \%$ EDTA may result in deteriora- tion of Biodentine's surface during perforation repair and root canal treatment.

KEYWORDS: Calcium silicate; endodontics; surface properties 